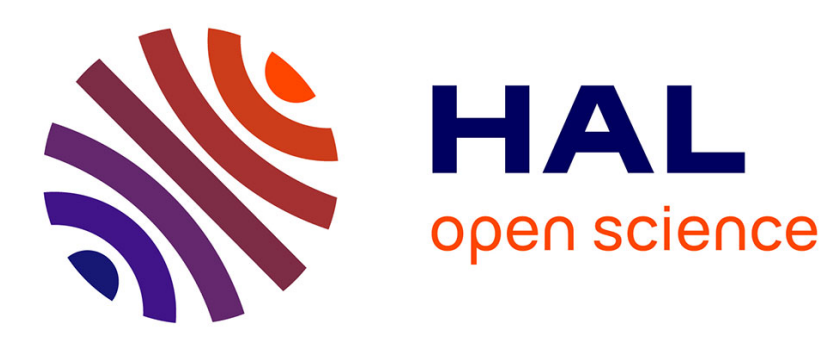

\title{
Models for daily global solar radiation for the Caribbean island of Trinidad
}

Keith de Souza, Roger Andrews

\section{To cite this version:}

Keith de Souza, Roger Andrews. Models for daily global solar radiation for the Caribbean island of Trinidad. Journal of Renewable and Sustainable Energy, 2015, 7, pp.013132. 10.1063/1.4909539 . halshs-02062304

\section{HAL Id: halshs-02062304 \\ https://shs.hal.science/halshs-02062304}

Submitted on 8 Mar 2019

HAL is a multi-disciplinary open access archive for the deposit and dissemination of scientific research documents, whether they are published or not. The documents may come from teaching and research institutions in France or abroad, or from public or private research centers.
L'archive ouverte pluridisciplinaire HAL, est destinée au dépôt et à la diffusion de documents scientifiques de niveau recherche, publiés ou non, émanant des établissements d'enseignement et de recherche français ou étrangers, des laboratoires publics ou privés. 


\section{A J Journal of Renewable and Sustainable Energy}

\section{Models for daily global solar radiation for the Caribbean island of Trinidad}

Keith De Souza and Roger Andrews

Citation: Journal of Renewable and Sustainable Energy 7, 013132 (2015); doi: 10.1063/1.4909539

View online: http://dx.doi.org/10.1063/1.4909539

View Table of Contents: http://scitation.aip.org/content/aip/journal/jrse/7/1?ver=pdfcov

Published by the AIP Publishing

\section{Articles you may be interested in}

Complex-valued forecasting of the global solar irradiation

J. Renewable Sustainable Energy 5, 043124 (2013); 10.1063/1.4818618

A clear sky irradiation assessment using the European Solar Radiation Atlas model and Shuttle Radar

Topography Mission database: A case study for Romanian territory

J. Renewable Sustainable Energy 5, 041807 (2013); 10.1063/1.4813001

Artificial neural network based computational model for the prediction of direct solar radiation in Indian zone

J. Renewable Sustainable Energy 4, 063146 (2012); 10.1063/1.4772677

Predicting global solar radiation for South America

J. Renewable Sustainable Energy 4, 043101 (2012); 10.1063/1.4729593

Hybrid neural network-particle swarm method to predict global radiation over the Norte Chico (Chile)

J. Renewable Sustainable Energy 4, 023108 (2012); 10.1063/1.3699616

\section{A|P| $\begin{aligned} & \text { Journal of } \\ & \text { Applied Physics }\end{aligned}$}

Journal of Applied Physics is pleased to announce André Anders as its new Editor-in-Chief 


\title{
Models for daily global solar radiation for the Caribbean island of Trinidad
}

\author{
Keith De Souza and Roger Andrews \\ Department of Physics, The University of the West Indies, St. Augustine, Trinidad
}

(Received 27 September 2014; accepted 8 February 2015; published online 20 February 2015)

In this study, calibration and validation data sets from 2001 to 2005 and 2006 to 2010, respectively, were used to develop various Angström-Prescott models: A five-year model and five-year dry and wet seasonal models to calculate monthly average daily global solar radiation on a horizontal surface and twelve monthly models to estimate average daily global solar radiation on a horizontal surface. Also, ten yearly models were developed for each year in the period 2001-2010. The regression coefficients $(a, b)$ for the five-year, dry season, and wet season models were found to be $(0.21,0.38),(0.21,0.38)$, and $(0.27,0.28)$, respectively. For the twelve monthly models, $a$ and $b$ varied over the ranges $0.19-0.37$ and $0.14-0.42$, respectively. For the ten yearly models, $a$ and $b$ varied over the ranges $0.15-0.31$ and $0.22-0.48$, respectively. The regression coefficients of the twelve monthly models yielded a linear relationship between $b$ and $a$ over a one-year time scale. Similarly, the ten yearly models also yielded a linear relationship between $b$ and $a$ over a ten-year time scale. For all the models, measured and calculated daily global solar radiation were compared by calculating the mean bias error, mean percentage error, root mean square error, correlation coefficient, Nash-Sutcliffe efficiency, and $p$-values based on t-statistics. Good agreement was found between the measured and calculated values and hence these models can be used in Trinidad. The single five-year model was found to be adequate in modelling the dry and wet seasons. Using the full data set, 2001-2010, the average daily global solar radiation, average total global solar radiation, average daily number of sunshine hours, and average total number of sunshine hours were determined to be $16.93 \pm 0.73 \mathrm{MJ} \mathrm{m}^{-2}$ day $^{-1}$, $2.56 \pm 0.11 \mathrm{GJ} \mathrm{m}^{-2}, 8.49 \pm 0.44 \mathrm{~h} \mathrm{day}^{-1}$, and $1282 \pm 67 \mathrm{~h}$, respectively, for the dry season; $15.52 \pm 0.81 \mathrm{MJ} \mathrm{m}^{-2} \mathrm{day}^{-1}, 3.32 \pm 0.17 \mathrm{GJ} \mathrm{m}^{-2}, 7.03 \pm 0.38 \mathrm{~h} \mathrm{day}^{-1}$, and $1504 \pm 81 \mathrm{~h}$, respectively, for the wet season; and $16.08 \pm 0.71 \mathrm{MJ} \mathrm{m}^{-2}$ day $^{-1}$, $5.87 \pm 0.26 \mathrm{GJ} \mathrm{m}^{-2}, 7.65 \pm 0.24 \mathrm{~h} \mathrm{day}^{-1}$, and $2792 \pm 83 \mathrm{~h}$, respectively, for the whole year. @ 2015 AIP Publishing LLC. [http://dx.doi.org/10.1063/1.4909539]

\section{INTRODUCTION}

The Republic of Trinidad and Tobago is a twin-island state in the Caribbean, located just off the northeast coast of Venezuela at $10^{\circ} 35^{\prime} \mathrm{N}$ latitude and $61^{\circ} 21^{\prime} \mathrm{W}$ longitude. Trinidad has an area of $4827 \mathrm{~km}^{2}$ while Tobago, the smaller of the two islands, has an area of $303 \mathrm{~km}^{2}$. The islands experience two seasonal climates due to their location, namely, the Tropical Maritime or dry season, which occurs from January to May followed by the Modified Moist Equatorial or wet season, which occurs from June to December. Trinidad has average minimum and maximum temperatures of $22.7^{\circ} \mathrm{C}$ and $31.3^{\circ} \mathrm{C}$, respectively. The mean annual rainfall ranges from a minimum of $1500 \mathrm{~mm}$ to a maximum of $3500 \mathrm{~mm}$ with most rainfall occurring during the months June-November.

Trinidad and Tobago is the leading producer of oil in the Caribbean and is considered to be one of the most industrialized nations in this region. The country's oil reserves are decreasing and environmental pollution is increasing due to industrialization. The abundance of sunshine and hence global solar radiation in Trinidad and Tobago facilitates the implementation of 
solar energy technologies thereby reducing the use of fossil fuels for the generation of electricity and hence the country's carbon footprint.

Global solar radiation data are used in many applications such as: photovoltaic systems (PV) design, solar thermal systems design, crop growth models, buildings design, and thermal comfort studies. For example, Markvart et al. ${ }^{1}$ used observed time series of solar radiation to construct a sizing curve to size a PV system in London. Martin et al. ${ }^{2}$ used time-series forecasting to predict daily global solar radiation for energy production planning in solar thermal power plants. De Jong and Stewart ${ }^{3}$ utilized global solar radiation data in crop growth models to estimate the daily plant growth and crop yields. In buildings design research, Catalina et al. ${ }^{4}$ developed a regression model to predict the monthly heating energy demands in residential buildings for temperate climates. In this case, the monthly average global solar radiation data on a horizontal surface was used in the calculation of the climate coefficient, which is a parameter in their energy prediction model. In the study of thermal comfort, La Gennusa et al. ${ }^{5}$ used the Fanger model to evaluate how a person's thermal balance is affected by solar radiation entering a thermally moderate indoor environment.

While global solar radiation data is important for numerous applications, in many developing countries, solar radiation data is not always available. Therefore, global solar radiation is estimated using more readily available climatological and meteorological parameters. For example, Bindi and Miglietta ${ }^{6}$ used daily maximum and minimum temperature and total daily rainfall from eleven countries to estimate daily global solar radiation. Almorox et al. ${ }^{7}$ used temperature and saturation vapor pressure data to estimate daily global solar radiation in Spain. Korachagaon and Bapat $^{8}$ used the generalized Iranna-Bapat's model to predict global solar radiation at any location based on temperature, wind speed, humidity, and moisture. El-Sebaii et al. ${ }^{9}$ developed correlations between monthly average daily global solar radiation on a horizontal surface and number of bright sunshine hours, mean daily ambient temperature, cloud cover, relative humidity, and maximum and minimum ambient temperature for Jeddah, Saudi Arabia. Duzen and Aydin, ${ }^{10}$ Liu et al., ${ }^{11}$ Wong and Chow, ${ }^{12}$ and Bakirci ${ }^{13}$ used the number of bright sunshine hours to estimate the monthly average daily global solar radiation on a horizontal surface by using the AngströmPrescott model. ${ }^{14}$ Chegaar and Chibani ${ }^{15}$ used two models to calculate global solar radiation for different Algerian locations. The first model uses sunshine duration and noon solar altitude while the second one is the Angström-Prescott model. Other methods for predicting global solar radiation include fuzzy logic, ${ }^{16,17}$ neural networks, ${ }^{18,19}$ and stochastic ${ }^{20,21}$ modelling.

With respect to Trinidad, Smith ${ }^{22}$ determined the Angström-Prescott equation for monthly average daily global solar radiation on a horizontal surface for Trinidad using data over approximately one year, 1951. The regression coefficients $(a, b)$ were found to be $(0.27,0.49)$. In this paper, a comprehensive study to develop various Angström-Prescott models over different time scales is undertaken using data over 2001-2010. Calibration and validation data sets from 2001 to 2005 and 2006 to 2010, respectively, were used to develop and evaluate certain models for global solar radiation on a horizontal surface. The objectives are to determine: (i) a five-year model and five-year dry and wet seasonal models to calculate monthly average daily global solar radiation using the calibration and validation data sets; (ii) ten yearly models from 2001 to 2010, to establish the relationship between $b$ and $a$ over a ten-year time scale; (iii) twelve monthly models to estimate average daily global solar radiation using the calibration and validation data sets as well as to establish the relationship between $b$ and $a$ over a one-year time scale; and (iv) the average daily global solar radiation, average total global solar radiation, average daily number of sunshine hours, and average total number of sunshine hours for the dry season, wet season, and whole year, respectively, using the full data set.

For the aforementioned models in (i), (ii), and (iii), measured and calculated daily global solar radiation were compared by calculating the mean bias error $(M B E)$, mean percentage error $(M P E)$, root mean square error (RMSE), correlation coefficient $(r)$, Nash-Sutcliffe efficiency (NSE), and p-values based on t-statistics.

This study will contribute significantly to solar energy applications and in particular, enable photovoltaic and hybrid solar-wind systems to be designed more efficiently and economically in Trinidad. In addition, energy-efficient building designs can be developed that optimize human thermal comfort thereby mitigating against sick-building syndrome. In the sphere of agriculture, 
where there is a thrust towards achieving food-security and self-sufficiency, this study can be used in crop growth models to predict and optimize crop yields as well as in thermal comfort studies for livestock productivity. These applications, if implemented, would reduce Trinidad's fossil fuel dependence and carbon footprint.

\section{THEORY}

\section{A. The Angström-Prescott model}

The Angström-Prescott model is a linear model used to estimate average global solar radiation on a horizontal surface. The general Angström-Prescott equation relates the average clearness index $\frac{\bar{H}}{H_{o}}$ to the average fraction of sunshine hours $\frac{\bar{n}}{N}$ by the equation (Angström ${ }^{23}$ and Prescott $^{14}$ )

$$
\frac{\bar{H}}{\bar{H}_{o}}=a+b \frac{\bar{n}}{\bar{N}}
$$

where $\bar{H}_{o}$ is the theoretical average extraterrestrial radiation, $\bar{H}$ is the measured average global solar radiation, $\bar{N}$ is the theoretical average number of sunshine hours per clear day, $\bar{n}$ is the measured average number of sunshine hours per day for direct solar radiation exceeding $120 \mathrm{~W}$ $\mathrm{m}^{-2}$, and $a, b$ are the regression coefficients.

In this paper, the averages considered are monthly average daily and average daily. The former is calculated by averaging daily values over a given month. The latter is calculated by averaging a daily value over a number of years; for example, global solar radiation for January 1 st over 5 years.

The daily extraterrestrial radiation, $H_{o}$, in $\mathrm{J} \mathrm{m}^{-2}$ day $^{-1}$ on a horizontal surface is given by (Duffie and Beckman ${ }^{24}$ )

$$
H_{0}=\left(\frac{86400 I_{s c}}{\pi}\right)\left[\cos \varphi \cos \delta \sin \omega_{s}+\left(\frac{\pi \omega_{s}}{180}\right) \sin \varphi \sin \delta\right]\left[1+0.033 \cos \left(\frac{360 x}{365}\right)\right],
$$

where $I_{s c}$ is the solar constant $\left(1367 \mathrm{~W} / \mathrm{m}^{2}\right), \varphi$ is the latitude of the location, $\delta$ is the sun declination angle, and $\omega_{s}$ is the sunset hour angle, all expressed in degrees. The following equations $\left(\operatorname{Sen}^{25}\right)$ define $\delta$ and $\omega_{s}$ as:

$$
\delta=23.45 \sin \left[360 \frac{(284+x)}{365}\right],-23.45^{\circ} \leq \delta \leq 23.45^{\circ},
$$

where $x$ is the day of the year; for example, January 1 st means $x=1$ and

$$
\omega_{s}=\cos ^{-1}(-\tan \varphi \tan \delta) .
$$

The theoretical number of sunshine hours per clear day, $N$, can be calculated using the equation,

$$
N=\frac{2}{15} \omega_{s} .
$$

\section{B. Statistical test parameters}

To determine how well the measured and calculated values agree with each other, six statistical test parameters are considered in this analysis. These include $M B E\left(\mathrm{MJ} \mathrm{m}^{-2} \mathrm{day}^{-1}\right.$ ), $\operatorname{MPE}(\%), R M S E\left(\mathrm{MJ} \mathrm{m}^{-2} \mathrm{day}^{-1}\right), r, N S E$, and $p$-values from t-statistics.

For better agreement between calculated and measured values, MBE, MPE, and RMSE lie closer to zero while for greater correlation, $r$ is closer to 1 . The RMSE is a measure of the short term accuracy of the model while $M B E$ and $M P E$ are measures of its long term accuracy. $R M S E \geq 0$ and has an ideal value of 0 . It gives a good measure of the accuracy of the calculated values. For an $M B E>0$ or $M B E<0$, the calculated value is overestimated or underestimated, 
respectively. An $M B E=0$ means that the calculated values are very good estimates of the measured values. The correlation coefficient $r$ is a statistical measure of how calculated and measured values vary in relation to each other and is defined as the ratio of the covariance to the product of the standard deviations of the measured and calculated values and ranges over $-1 \leq r \leq 1$. Greater correlation and anti-correlation between calculated and measured values occur for $r$ closer to 1 and $r$ closer to -1 , respectively. The NSE is defined as one minus the sum of the squared differences between the calculated and measured values normalized by the variance of the measured values and ranges over $-\infty \leq N \mathrm{SE} \leq 1$. For $N S E<0$, the mean of the measured data is a better predictor than the model while for NSE $>0$ the model is the better predictor. The efficiency of the model improves as NSE approaches 1. The $p$-value indicates whether the difference between the means of the measured and calculated values is statistically significant at a given confidence level. For example, a two-tailed test at 0.05 level of significance means that if $p>0.05$, the model is accepted as valid but if $p<0.05$, the model is rejected with a $5 \%$ chance that it is indeed valid.

The following variables and statistical test parameters are defined as:

$\bar{H}_{i, \text { calc }}=i$ th calculated value of average global solar radiation,

$\bar{H}_{i, \text { meas }}=i$ th measured value of average global solar radiation,

$n=$ no. of values of $\left(\bar{H}_{i, \text { calc }}, \bar{H}_{i, \text { meas }}\right)$,

$i=1, \ldots, n$,

$\bar{H}_{\text {calc }}=$ average of $\bar{H}_{i, \text { calc }}$,

$\bar{H}_{\text {meas }}=$ average of $\bar{H}_{i, \text { meas }}$,

$$
\begin{gathered}
M B E=\frac{1}{n} \sum_{i=1}^{n}\left(\bar{H}_{i, \text { calc }}-\bar{H}_{i, \text { meas }}\right), \\
\operatorname{MPE}(\%)=\frac{1}{n} \sum_{i=1}^{n}\left(\frac{\bar{H}_{i, \text { calc }}-\bar{H}_{i, \text { meas }}}{\bar{H}_{i, \text { meas }}}\right) \times 100, \\
r M S E=\left[\frac{1}{n} \sum_{i=1}^{n}\left(\bar{H}_{i, \text { calc }}-\bar{H}_{i, \text { meas }}\right)^{2}\right]^{1 / 2}, \\
\sqrt{\sum_{\mathrm{i}=1}^{\mathrm{n}}\left(\bar{H}_{i, \text { meas }}-\bar{H}_{\text {meas }}\right)^{2}} \sqrt{\sum_{\mathrm{i}=1}^{\mathrm{n}}\left(\bar{H}_{i, \text { calc }}-\bar{H}_{\text {calc }}\right)^{2}} \\
N S E=1-\frac{\sum_{i=1}^{n}\left(\bar{H}_{i, \text { calc }}-\bar{H}_{i, \text { meas }}\right)^{2}}{\sum_{i=1}^{n}\left(\bar{H}_{i, \text { meas }}-\bar{H}_{\text {meas }}\right)^{2}} .
\end{gathered}
$$

Probability values or $p$-values were calculated by applying t-statistics assuming a two-tailed test at a $95 \%$ confidence level and unequal variances of the calculated and measured global solar radiation data.

\section{METHODOLOGY}

Data of measured hourly global solar radiation and corresponding measured number of sunshine hours were obtained from the Trinidad and Tobago Meteorological Services which is located at $10^{\circ} 35^{\prime} \mathrm{N}$ latitude, $61^{\circ} 21^{\prime} \mathrm{W}$ longitude, and $21.95 \mathrm{~m}$ above mean sea level. A digital Eppley Black and White pyranometer with measurement uncertainty of $<2 \%$ was used to measure global solar radiation data while sunshine hours were measured using an analog CampbellStokes sunshine recorder with measurement uncertainty of $\pm 0.05 \mathrm{~h}$. The Trinidad and Tobago Meteorological Services, as a member of the World Meteorological Organization, follows the organization's standards and best practices with respect to maintenance and calibration of the instruments. 
The data were collected for the years 2001-2010. There was a complete data set of sunshine hours but there were missing global solar radiation data in the following periods:

(i) 2005: January, October 8th-October 17th, December 21st-December 28th,

(ii) 2006: January (13 non-consecutive days), April 13th-April 30th, August 15th-August 27th,

(iii) 2007: April 6th-April 13th,

(iv) 2008: November and December,

(v) 2010: June 1st-August 11th.

All analyses utilized data that were subjected to quality control using the following criteria:

(i) Days with both global solar radiation and sunshine hours data were used to calculate averages.

(ii) Days where global solar radiation was less than extraterrestrial solar radiation were used to calculate averages.

(iii) Days where the number of sunshine hours was less than the theoretical maximum number of sunshine hours were used to calculate averages.

All data provided, satisfied criteria (ii) and (iii).

By applying quality control, the total number of measured daily global solar radiation data points available was 3447 which equaled the corresponding number of measured daily sunshine hour data points. Of these, the calibration data set 2001-2005 consisted of 1807 data points while the validation data set comprised 1640 data points.

Angström-Prescott models were developed for different time scales. In Subsection III A, a five-year monthly average daily global solar radiation model for 2001-2005 is developed and evaluated using the independent data set 2006-2010 and statistical test parameters: MBE, MPE, $R M S E, r, N S E$, and $p$-values. In Subsection III B, five-year seasonal monthly average daily global solar radiation models for 2001-2005 are developed and evaluated using the independent data set 2006-2010 and the same statistical test parameters. Seasonal and whole-year variation of global solar radiation and sunshine hours is presented. Subsection IIIC presents ten yearly models, one for each year in the period 2001-2010. In Subsection III D, twelve monthly models are developed using monthly data over the period 2001-2005. Finally in Subsection IIIE, linear relationships between the regression coefficients $b$ and $a$ are established.

\section{A. The five-year Angström-Prescott model}

Five-year measured monthly average daily global solar radiation $(\bar{H})$ and sunshine hours $(\bar{n})$ were computed from hourly data. Similar five-year theoretical monthly averages for extraterrestrial radiation $\left(\bar{H}_{0}\right)$ and number of sunshine hours per clear day $(\bar{N})$ were obtained. Linear regression analysis was done for $\frac{\bar{H}}{H_{o}}$ and $\frac{\bar{n}}{N}$ from which the regression coefficients $a$ and $b$ were determined and the Angström-Prescott model obtained. For each validation year, calculated values of monthly average daily global solar radiation were obtained from the model and plotted against corresponding values of measured monthly average daily global solar radiation. A 1:1 line was plotted on the graph to show the deviations of calculated values from measured values. In the ideal case, (measured, calculated) points lie on the 1:1 line. The statistical test parameters were then calculated.

\section{B. Five-year seasonal Angström-Prescott models and seasonal and whole-year variation of global solar radiation and sunshine hours}

Similar to the procedure for obtaining the five-year model in Subsection III A, five-year seasonal models for the period 2001-2005 were developed. The statistical test parameters were then calculated using measured monthly average daily global solar radiation from the 
independent data set 2006-2010. The five-year model in Subsection III A was applied to the dry and wet seasons, respectively, to compare its performance with the seasonal models.

Plots of measured monthly average daily global solar radiation and number of sunshine hours against months of the year were generated. The average daily global solar radiation, average total global solar radiation, average daily number of sunshine hours, and average total number of sunshine hours were determined for the dry season, wet season, and whole year.

\section{The ten yearly Angström-Prescott models}

Similar to the procedure for obtaining the five-year model in Subsection III A, ten Angström-Prescott models for each year over the period 2001-2010 were determined. Each model was applied to data of its respective year to calculate monthly average daily global solar radiation. Similar 1:1 line graphs were produced and statistical test parameters determined.

\section{Five-year monthly Angström-Prescott models}

Five-year measured average daily global solar radiation $(\bar{H})$ and measured average daily number of sunshine hours $(\bar{n})$ were computed using calibration data 2001-2005. Similar fiveyear theoretical daily averages for extraterrestrial radiation $\left(\bar{H}_{o}\right)$ and number of sunshine hours per clear day $(\bar{N})$ were obtained. Linear regression analysis for each month was done for $\frac{\bar{H}}{H_{o}}$ and $\frac{\bar{n}}{N}$ from which the regression coefficients $a$ and $b$ were determined and the monthly AngströmPrescott models obtained. Graphs of calculated values of average daily global solar radiation against corresponding values of measured daily global solar radiation with 1:1 lines were produced and statistical test parameters calculated.

\section{E. Linear relationships between the regression coefficients $b$ and $a$}

Mathematical relationships between regression coefficients $b$ and $a$ were established by performing regression analysis on first the ten pairs of $(b, a)$ from the yearly models of Subsection III C and second from the twelve pairs of $(b, a)$ values from the monthly models of Subsection III D and the corresponding regressions lines plotted. The relationships were then compared to three published theoretical models applied to Trinidad.

\section{RESULTS AND DISCUSSION}

\section{A. The five-year Angström-Prescott model}

For the five-year model, the regression coefficients, $a$ and $b$, for the Angström-Prescott model were determined to be 0.21 and 0.38 , respectively. Hence, the Angström-Prescott model is given by

$$
\frac{\bar{H}}{\bar{H}_{o}}=0.21+0.38 \frac{\bar{n}}{\bar{N}} .
$$

Figure 1 shows 1:1 lines and point plots of calculated versus measured monthly average daily global solar radiation for the years 2006-2010 based on the five-year Angström-Prescott model.

Based on the validation data set, the values of measured global solar radiation varied from a minimum of $12.25 \mathrm{MJ} \mathrm{m}^{-2}$ day $^{-1}$ in January 2006 to a maximum of $19.46 \mathrm{MJ} \mathrm{m}^{-2}$ day $^{-1}$ in April 2006.

Table I shows the calculated statistical test parameters for the five-year model for each year in the period 2006-2010. Over the years, $M B E$ values ranged from -0.19 to 0.65 with underestimation of the calculated values for two years (2007 and 2008) and overestimation for the remaining three years. $M P E$ values were acceptable, ranging from $-1.13 \%$ to $4.47 \%$ and RMSE ranged from 0.54 to 0.92 .

Good correlation was obtained for all years with correlation coefficients ranging from 0.80 to 0.96 with 2009 having the lowest correlation. NSE values ranged from 0.60 to 0.90 with 2009 having the lowest efficiency. Since all NSE values are greater than zero, the model is a 

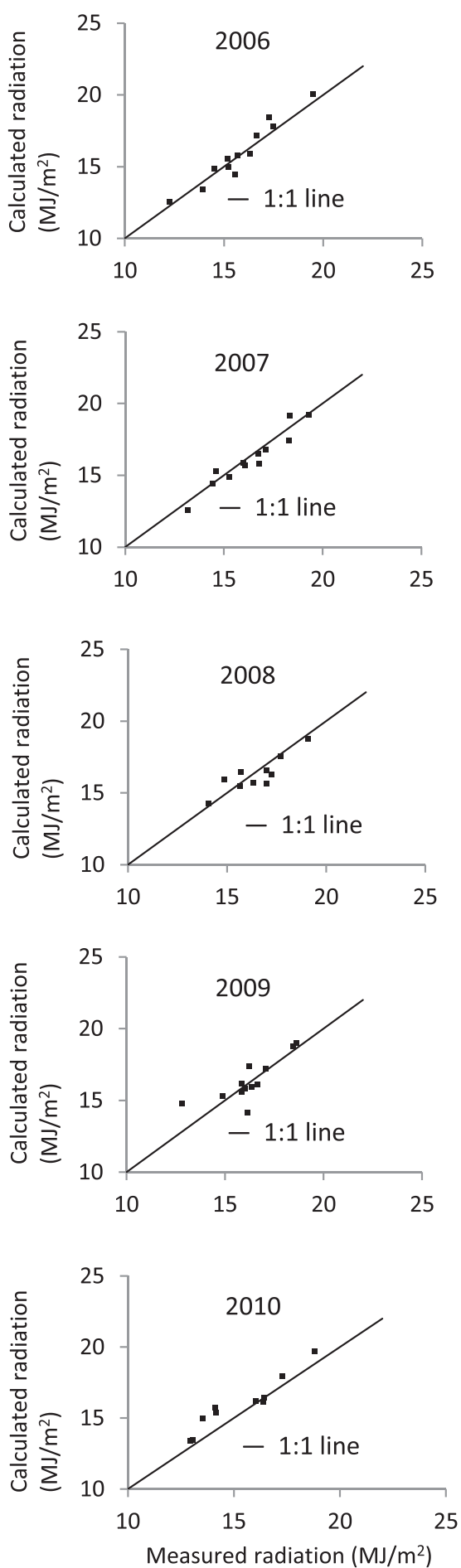

FIG. 1. 1:1 lines and plots of calculated versus measured monthly average daily global solar radiation for the years 2006-2010 based on the five-year Angström-Prescott model.

better predictor than the mean of the measured values. The p-values ranged from 0.46 to 0.86 showing that the difference between the means of the measured and calculated values is not statistically significant at the $95 \%$ confidence level. Therefore, the model provides a good estimation of the measured values. Hence, a five-year model is adequate for predicting monthly average daily global solar radiation. 
TABLE I. Statistical test parameters for the five-year Angström-Prescott model applied to 2006-2010.

\begin{tabular}{ccccccc}
\hline \hline Year & MBE $\left(\mathrm{MJ} \mathrm{m}^{-2} \mathrm{day}^{-1}\right)$ & $M P E(\%)$ & RMSE $\left(\mathrm{MJ} \mathrm{m}^{-2} \mathrm{day}^{-1}\right)$ & $r$ & NSE & $p$-value \\
\hline 2006 & 0.15 & 0.82 & 0.60 & 0.96 & 0.89 & 0.86 \\
2007 & -0.18 & -1.13 & 0.54 & 0.96 & 0.90 & 0.81 \\
2008 & -0.19 & -0.95 & 0.72 & 0.86 & 0.72 & 0.76 \\
2009 & 0.13 & 1.04 & 0.92 & 0.80 & 0.60 & 0.84 \\
2010 & 0.65 & 4.47 & 0.88 & 0.95 & 0.78 & 0.46 \\
Range & $-0.19-0.65$ & $-1.13-4.47$ & $0.54-0.92$ & $0.80-0.96$ & $0.60-0.90$ & $0.46-0.86$ \\
\hline \hline
\end{tabular}

\section{B. Five-year seasonal Angström-Prescott models and seasonal and whole-year variation of global solar radiation and sunshine hours}

The dry season, occurs from January to May and the wet season, from June to December. The regression coefficients, $(a, b)$ for the dry season and wet season models were found to be $(0.21,0.38)$ and $(0.27,0.28)$, respectively.

Hence, the Angström-Prescott model for the dry season is given by

$$
\frac{\bar{H}}{\bar{H}_{o}}=0.21+0.38 \frac{\bar{n}}{\bar{N}},
$$

and that for the wet season is given by

$$
\frac{\bar{H}}{\bar{H}_{o}}=0.27+0.28 \frac{\bar{n}}{\bar{N}} .
$$

It should be noted that the dry season model and the five-year model in Subsection IV A are identical to two decimal places. This implies that the dry season model effectively captures the yearly dependence of monthly average daily global solar radiation on average fraction of sunshine hours. With respect to the wet season model, the $a$ coefficient is greater than that for the dry season model. This is due to the higher amount of diffuse radiation present on the cloudier days of the rainy season when $\bar{n}=0$. In addition, the sum of the regression coefficients, $a+b$, for the wet season is less than that for the dry season. This implies that on clear sky days, when $\frac{\bar{n}}{N}=1$, the total global radiation reaching the earth's surface is reduced in the wet season which is due to greater amounts of water vapor in the atmosphere at this time.

Table II shows the calculated statistical test parameters for the five-year dry season model for each year in the period 2006-2010. Over the years, $M B E$ values ranged from -0.10 to 0.64 with underestimation of the calculated values for two years (2007 and 2008) and overestimation for the remaining three years. $M P E$ values were acceptable, ranging from $-3.75 \%$ to $3.79 \%$ and $R M S E$ ranged from 0.54 to 1.32 .

Good correlation was obtained for all years with correlation coefficients ranging from 0.80 to 0.99 with 2009 having the lowest correlation. NSE values ranged from 0.62 to 0.91 with 2008 having the lowest efficiency. Since all NSE values are greater than zero, the model is a better predictor than the mean of the measured values. The $p$-values ranged from 0.42 to 0.96

TABLE II. Statistical test parameters for the five-year dry season Angström-Prescott model applied to 2006-2010 for the months of January-May.

\begin{tabular}{ccccccc}
\hline \hline Year & MBE $\left(\mathrm{MJ} \mathrm{m}^{-2} \mathrm{day}^{-1}\right)$ & $M P E(\%)$ & RMSE $\left(\mathrm{MJ} \mathrm{m}^{-2} \mathrm{day}^{-1}\right)$ & $r$ & NSE & $p$-value \\
\hline 2006 & 0.64 & 3.79 & 0.72 & 0.99 & 0.91 & 0.72 \\
2007 & -0.10 & -0.60 & 0.57 & 0.93 & 0.77 & 0.92 \\
2008 & -0.64 & -3.75 & 0.79 & 0.94 & 0.27 & 0.42 \\
2009 & 0.07 & 0.98 & 1.30 & 0.80 & 0.62 & 0.96 \\
2010 & 0.32 & 1.75 & 0.54 & 0.99 & 0.70 & 0.72 \\
Range & $-0.10-0.64$ & $-3.75-3.79$ & $0.54-1.32$ & $0.80-0.99$ & $0.62-0.91$ & $0.42-0.96$ \\
\hline \hline
\end{tabular}


TABLE III. Statistical test parameters for the five-year wet season Angström-Prescott model applied to 2006-2010 for the months of June-December.

\begin{tabular}{lcccccc}
\hline \hline Year & $M B E\left(\mathrm{MJ} \mathrm{m}^{-2} \mathrm{day}^{-1}\right)$ & $M P E(\%)$ & $R M S E\left(\mathrm{MJ} \mathrm{m}^{-2} \mathrm{day}^{-1}\right)$ & $r$ & NSE & $p$-value \\
\hline 2006 & -0.17 & -1.13 & 0.59 & 0.76 & 0.32 & 0.71 \\
2007 & -0.23 & -1.40 & 0.61 & 0.90 & 0.78 & 0.75 \\
2008 & 0.28 & 1.95 & 0.65 & 0.80 & 0.56 & 0.66 \\
2009 & -0.13 & -0.82 & 0.53 & 0.75 & 0.33 & 0.75 \\
2010 & 1.05 & 7.62 & 1.19 & 0.92 & -4.55 & 0.11 \\
Range & $-0.17-1.05$ & $-1.40-7.62$ & $0.53-1.19$ & $0.75-0.92$ & $-4.55-0.78$ & $0.11-0.75$ \\
\hline \hline
\end{tabular}

TABLE IV. Statistical test parameters for the five-year model applied to the wet season.

\begin{tabular}{ccccccc}
\hline \hline Year & MBE $\left(\mathrm{MJ} \mathrm{m}^{-2} \mathrm{day}^{-1}\right)$ & MPE $(\%)$ & RMSE $\left(\mathrm{MJ} \mathrm{m}^{-2} \mathrm{day}^{-1}\right)$ & $r$ & NSE & $p$-value \\
\hline 2006 & -0.18 & -1.19 & 0.52 & 0.80 & 0.47 & 0.69 \\
2007 & -0.22 & -1.36 & 0.52 & 0.93 & 0.84 & 0.77 \\
2008 & 0.29 & 1.99 & 0.64 & 0.81 & 0.57 & 0.67 \\
2009 & 0.18 & 1.14 & 0.54 & 0.72 & 0.29 & 0.66 \\
2010 & 1.02 & 7.38 & 1.14 & 0.96 & -4.04 & 0.40 \\
Range & $-0.18-1.02$ & $-1.36-7.38$ & $0.52-1.14$ & $0.72-0.96$ & $-4.04-0.84$ & $0.40-0.77$ \\
\hline \hline
\end{tabular}

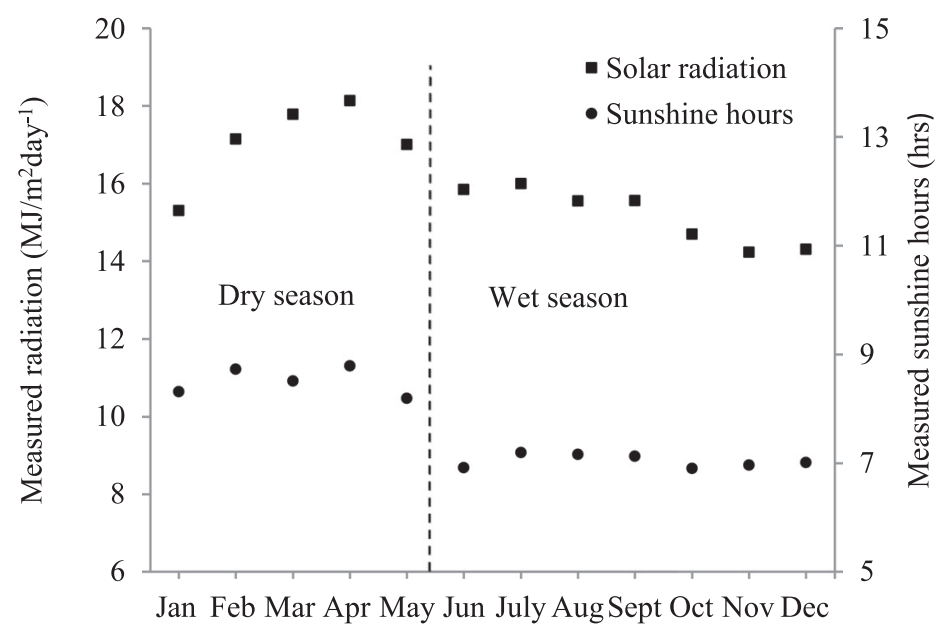

Month

FIG. 2. Monthly variation of measured monthly average daily global solar radiation and sunshine hours for the period 2001-2010.

TABLE V. Measured global solar radiation and sunshine hours for the dry season, wet season, and whole year.

\begin{tabular}{lccc}
\hline \hline Global solar radiation and sunshine hours & $\begin{array}{c}\text { Dry season } \\
(151 \text { days })\end{array}$ & $\begin{array}{c}\text { Wet season } \\
(214 \text { days })\end{array}$ & $\begin{array}{c}\text { Whole year } \\
\text { (365 days) }\end{array}$ \\
\hline Average daily global solar radiation $\left(\mathrm{MJ} \mathrm{m}^{-2}\right.$ day $\left.^{-1}\right)$ & $16.93 \pm 0.73$ & $15.52 \pm 0.81$ & $16.08 \pm 0.71$ \\
Average total global solar radiation $\left(\mathrm{GJ} \mathrm{m}^{-2}\right)$ & $2.56 \pm 0.11$ & $3.32 \pm 0.17$ & $5.87 \pm 0.26$ \\
Average daily number of sunshine hours $\left(\mathrm{h} \mathrm{day}{ }^{-1}\right)$ & $8.49 \pm 0.44$ & $7.03 \pm 0.38$ & $7.65 \pm 0.24$ \\
Average total number of sunshine hours (h) & $1282 \pm 67$ & $1504 \pm 81$ & $2792 \pm 83$ \\
\hline \hline
\end{tabular}


showing that the difference between the means of the measured and calculated values is not statistically significant at the $95 \%$ confidence level. Therefore, the model provides a good estimation of the measured values. Hence, the dry season model is adequate in predicting monthly average daily global solar radiation over the months January-May. It should be noted, however, that because the five-year model and the dry season model are identical, then applying the fiveyear model to the dry season would yield identical statistical test parameters as in Table II and hence the five-year model is well suited to the dry season.

Table III shows the calculated statistical test parameters for the five-year wet season model for each year in the period 2006-2010. Over the years, $M B E$ values ranged from -0.17 to 1.05 with underestimation of the calculated values for three years (2006, 2007, and 2009) and overestimation for the remaining two years. MPE values were acceptable, ranging from $-1.40 \%$ to $7.62 \%$ and RMSE ranged from 0.53 to 1.19 . Good correlation was obtained for all years with correlation coefficients ranging from 0.75 to 0.92 with 2009 having the lowest correlation. NSE values ranged from -4.55 to 0.78 with 2010 having the lowest efficiency. The model is a better predictor than the mean of the measured values for all the years except 2010 for which NSE is less than zero. The $p$-values ranged from 0.11 to 0.75 showing that the difference between the means of the measured and calculated values is not statistically significant at the $95 \%$ confidence level.

Comparing the ranges of the statistical test parameters in Tables II and III, it is observed that the dry season model performs better than the wet season model. Table IV shows the statistical test parameters for the five-year model (Subsection IV A) applied to the wet season. It should be noted that the statistical test parameters are similar to those obtained in Table III.

In summary, there is no advantage in using seasonal models over the five-year model of Subsection IV A since the statistical test parameters of the five-year model applied to either season gives similar results to each seasonal model.

Figure 2 shows plots of the monthly variation of measured monthly average daily global solar radiation and number of sunshine hours for the period 2001-2010. The dry season occurs from January to May (151 days) and the wet season from June to December (214 days). The maximum global solar radiation occurs in April with minima in November and December. Table V summarizes measured global solar radiation and sunshine hours for the dry season, wet season, and whole year. The average daily global solar radiation, average total global solar radiation, average daily number of sunshine hours, and average total number of sunshine hours are presented. The average daily global solar radiation for the dry season exceeds that of the wet season by $1.41 \mathrm{MJ} \mathrm{m}^{-2} \mathrm{day}^{-1}$. However, the average total global solar radiation for the dry season is less than that for the wet season by $0.76 \mathrm{GJ} \mathrm{m}^{-2}$ which is due to a longer wet season. The average daily number of sunshine hours for the dry season exceeds that of the wet season by $1.46 \mathrm{~h} \mathrm{day}^{-1}$. However, the average total number of sunshine hours for the dry season is less than that for the wet season by $382 \mathrm{~h}$ again due to the longer wet season. Whole year averages are included for use in applications for which seasonal variation is not critical.

TABLE VI. Regression coefficients $a$ and $b$ for the yearly Angström-Prescott models from 2001 to 2010.

\begin{tabular}{ccc}
\hline \hline Year & $\mathrm{a}$ & $\mathrm{b}$ \\
\hline 2001 & 0.26 & 0.32 \\
2002 & 0.23 & 0.35 \\
2003 & 0.25 & 0.32 \\
2004 & 0.18 & 0.41 \\
2005 & 0.16 & 0.44 \\
2006 & 0.25 & 0.31 \\
2007 & 0.22 & 0.38 \\
2008 & 0.15 & 0.48 \\
2009 & 0.31 & 0.22 \\
2010 & 0.17 & 0.41 \\
Range & $0.15-0.31$ & $0.22-0.48$ \\
\hline \hline
\end{tabular}



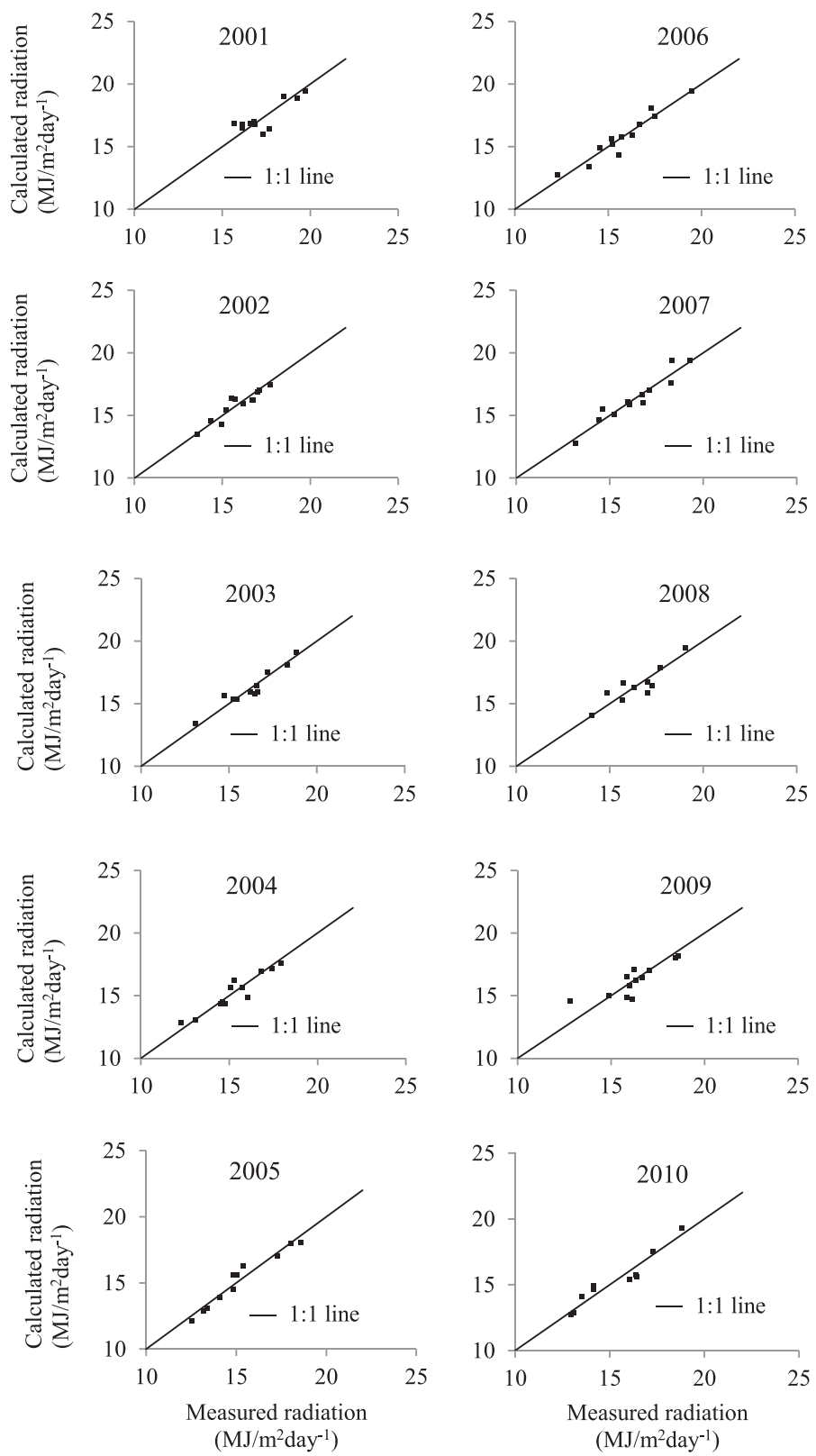

FIG. 3. 1:1 lines and plots of calculated versus measured monthly average daily global solar radiation for the years 2001-2010 based on yearly Angström-Prescott models.

\section{The ten yearly Angström-Prescott models}

Table VI gives the regression coefficients $a$ and $b$ for the yearly Angström-Prescott models from 2001 to 2010. The regression coefficients $a$ and $b$ varied from 0.15 to 0.31 and 0.22 to 0.48 , respectively.

The higher value of $a$ in 2009 is due to a higher amount of diffuse radiation present on the cloudier days of that year when $\bar{n}=0$. In addition, the sum of the regression coefficients, $a+b$ for 2009 is less than that for the other nine years which implies that on clear sky days, when $\frac{\bar{n}}{N}=1$, the total global radiation reaching the earth's surface is reduced probably due to greater amounts of water vapor in the atmosphere. Figure 3 shows 1:1 lines and point plots of calculated versus measured monthly average daily global solar radiation for the years 2001-2010. 
TABLE VII. Statistical test parameters for yearly Angström-Prescott models from 2001 to 2010.

\begin{tabular}{lcccccc}
\hline \hline Year & MBE $\left(\mathrm{MJ} \mathrm{m}^{-2} \mathrm{day}^{-1}\right)$ & $M P E(\%)$ & RMSE $\left(\mathrm{MJ} \mathrm{m}^{-2} \mathrm{day}^{-1}\right)$ & $R$ & NSE & $p$-value \\
\hline 2001 & 0.006 & 0.174 & 0.732 & 0.820 & 0.665 & 0.992 \\
2002 & 0.001 & 0.059 & 0.432 & 0.931 & 0.866 & 0.999 \\
2003 & -0.002 & 0.085 & 0.446 & 0.956 & 0.915 & 0.998 \\
2004 & -0.005 & 0.096 & 0.523 & 0.944 & 0.890 & 0.994 \\
2005 & 0.015 & 0.074 & 0.461 & 0.972 & 0.941 & 0.986 \\
2006 & 0.017 & 0.129 & 0.510 & 0.961 & 0.918 & 0.983 \\
2007 & 0.018 & 0.108 & 0.516 & 0.958 & 0.911 & 0.982 \\
2008 & 0.011 & 0.158 & 0.650 & 0.889 & 0.778 & 0.987 \\
2009 & -0.002 & 0.288 & 0.805 & 0.833 & 0.694 & 0.997 \\
2010 & 0.013 & 0.157 & 0.562 & 0.956 & 0.911 & 0.988 \\
Range & $-0.005-0.018$ & $0.059-0.288$ & $0.432-0.805$ & $0.820-0.972$ & $0.665-0.941$ & $0.982-0.999$ \\
\hline \hline
\end{tabular}

Table VII shows the calculated statistical test parameters for the Angström-Prescott model for each year. Over the years, $M B E$ values ranged from -0.005 to 0.018 with underestimation of the calculated values for three years $(2003,2004$, and 2009) and overestimation for the remaining seven years but good agreement between measured and calculated values for all years. MPE values were acceptable, ranging from $0.059 \%$ to $0.288 \%$ and $R M S E$ ranged from 0.432 to 0.805 .

Good correlation was obtained for all years with $r$ ranging from 0.820 to 0.972 with 2001 having the lowest correlation. NSE values ranged from 0.665 to 0.941 with 2001 having the lowest efficiency. Since all NSE values are greater than zero, each yearly model is a better predictor than the mean of the corresponding measured values. The $p$-values ranged from 0.982 to 0.999 showing that the difference between the means of the measured and calculated values is not statistically significant at the $95 \%$ confidence level. Therefore, the yearly models provide good estimates of their corresponding measured values and would be useful in computing values for missing monthly average global solar radiation data for the period 2001-2010.

\section{Five-year monthly Angström-Prescott models}

Table VIII shows regression coefficients $a$ and $b$ for the twelve monthly Angström-Prescott models using calibration data 2001-2005. The regression coefficients $a$ and $b$ varied from 0.18

TABLE VIII. Regression coefficients $a$ and $b$ for the for twelve monthly Angström-Prescott models using data from the period 2001-2005.

\begin{tabular}{lcc}
\hline \hline Month & $\mathrm{a}$ & $\mathrm{b}$ \\
\hline January & 0.25 & 0.33 \\
February & 0.18 & 0.41 \\
March & 0.23 & 0.37 \\
April & 0.23 & 0.34 \\
May & 0.25 & 0.30 \\
June & 0.20 & 0.42 \\
July & 0.19 & 0.40 \\
August & 0.23 & 0.32 \\
September & 0.35 & 0.14 \\
October & 0.20 & 0.37 \\
November & 0.26 & 0.28 \\
December & 0.37 & 0.17 \\
Range & $0.18-0.37$ & $0.14-0.42$ \\
\hline \hline
\end{tabular}



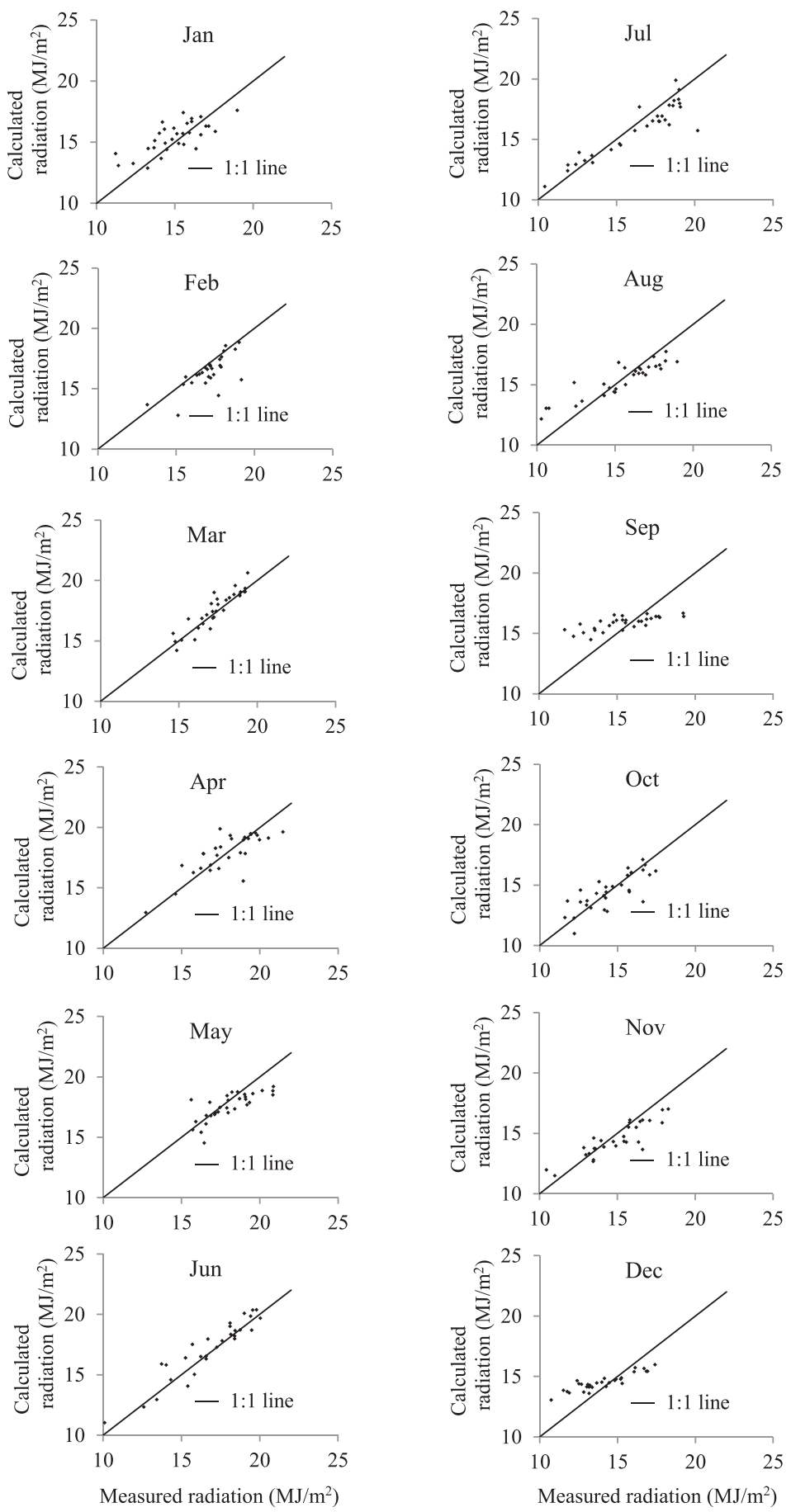

FIG. 4. 1:1 lines and plots of calculated versus measured average daily global solar radiation for the years 2006-2010 based on the five-year monthly Angström-Prescott models.

to 0.37 and 0.14 to 0.42 , respectively. September and December have higher values of $a$ which as stated earlier may be due to higher amounts of diffuse radiation present on the cloudier days of those months. Figure 4 shows point plots and 1:1 lines for calculated versus measured average daily global solar radiation for each of twelve months based on the respective AngströmPrescott model.

Table VIII gives the regression coefficients $a$ and $b$ for the monthly Angström-Prescott models using data from 2001 to 2005. 
TABLE IX. Statistical test parameters for twelve monthly Angström-Prescott models using average daily measured global solar radiation and measured sunshine hours computed over the period 2001-2005.

\begin{tabular}{lcccccc}
\hline \hline Year & MBE $\left(\mathrm{MJ} \mathrm{m}^{-2} \mathrm{day}^{-1}\right)$ & $M P E(\%)$ & RMSE $\left(\mathrm{MJ} \mathrm{m}^{-2} \mathrm{day}^{-1}\right)$ & $r$ & NSE & $p$-value \\
\hline January & 0.405 & 3.372 & 1.236 & 0.731 & 0.478 & 0.298 \\
February & -0.676 & -3.857 & 1.169 & 0.726 & 0.098 & 0.058 \\
March & 0.246 & 1.405 & 0.675 & 0.916 & 0.995 & 0.523 \\
April & 0.010 & 0.395 & 1.147 & 0.794 & 0.986 & 0.983 \\
May & -0.460 & -2.278 & 1.073 & 0.760 & 0.989 & 0.182 \\
June & 0.414 & 3.022 & 0.957 & 0.951 & 0.990 & 0.562 \\
July & -0.438 & -1.829 & 1.235 & 0.926 & 0.981 & 0.518 \\
August & -0.011 & 1.274 & 1.223 & 0.921 & 0.980 & 0.955 \\
September & 0.470 & 4.330 & 1.609 & 0.727 & 0.964 & 0.263 \\
October & -0.049 & 0.090 & 1.050 & 0.780 & 0.982 & 0.905 \\
November & -0.314 & -0.995 & 1.178 & 0.888 & 0.977 & 0.528 \\
December & 0.490 & 4.501 & 1.234 & 0.905 & 0.974 & 0.151 \\
Range & $-0.676-0.490$ & $-3.857-4.501$ & $0.675-1.609$ & $0.726-0.951$ & $0.098-0.995$ & $0.058-0.955$ \\
\hline \hline
\end{tabular}

The regression coefficients $a$ and $b$ varied from 0.18 to 0.37 and 0.14 to 0.42 , respectively. The computed average values and standard deviations for $a$ and $b$ in the dry season (January-May) are: $a=0.23 \pm 0.03$ and $b=0.35 \pm 0.04$ while for the rainy season (June-December) $a=0.26 \pm 0.07$ and $b=0.30 \pm 0.11$ which shows that the variations of the regression coefficients are larger in the wet season than in the dry season. Further work on models for the regression coefficients as functions of clearness index, average fraction of sunshine hours, cloud cover, etc., can be undertaken to establish the differences in the variations of the coefficients in the dry and wet season.

Table IX shows the calculated statistical test parameters for the Angström-Prescott model for each month using data over the period 2001-2005. Over the months, $M B E$ values ranged from -0.676 to 0.490 with underestimation of the calculated values for six months (February, May, July, August, October, and November) and overestimation for the remaining six months but very good agreement between measured and calculated values for all months. MPE values were acceptable, ranging from $-3.857 \%$ to $4.501 \%$ and RMSE ranged from 0.675 to 1.609 . Good correlation was obtained for all months with $r$ ranging from 0.726 to 0.951 with February having the lowest correlation. NSE values ranged from 0.098 to 0.995 with February having the lowest efficiency. Since all NSE values are greater than zero, each monthly model is a better predictor than the mean of the corresponding measured values. The $p$-values ranged from 0.058 to 0.955 with February having the lowest $p$-value. The range indicates that the difference between the means of the measured and calculated values is not statistically significant at the 95\% confidence level. The low NSE and $p$-values in Table IX can be attributed to the limited number of calibration years used in which only five data points from the five years were used to compute daily averages. It is expected that if larger calibration and validation data sets are used, the low NSE and $p$-values should improve significantly. Generally, the monthly models do provide good estimates of their corresponding measured values.

\section{E. Linear relationships between the regression coefficients $b$ and $a$}

Figure 5 is a plot showing the linear relationship between the regression coefficients $b$ and $a$ given in Table VI for the yearly models. The linear relationship is given as $b=-1.40 a+0.67$ with a correlation coefficient $r=-0.98$. Figure 6 is a plot showing the linear relationship between the regression coefficients $b$ and $a$ given in Table VIII for the monthly models. The linear relationship obtained is $b=-1.52 a+0.70$ with a correlation coefficient $r=-0.97$. Thus, both the yearly and monthly models yielded linear relationships between $b$ and $a$ with similar correlation 


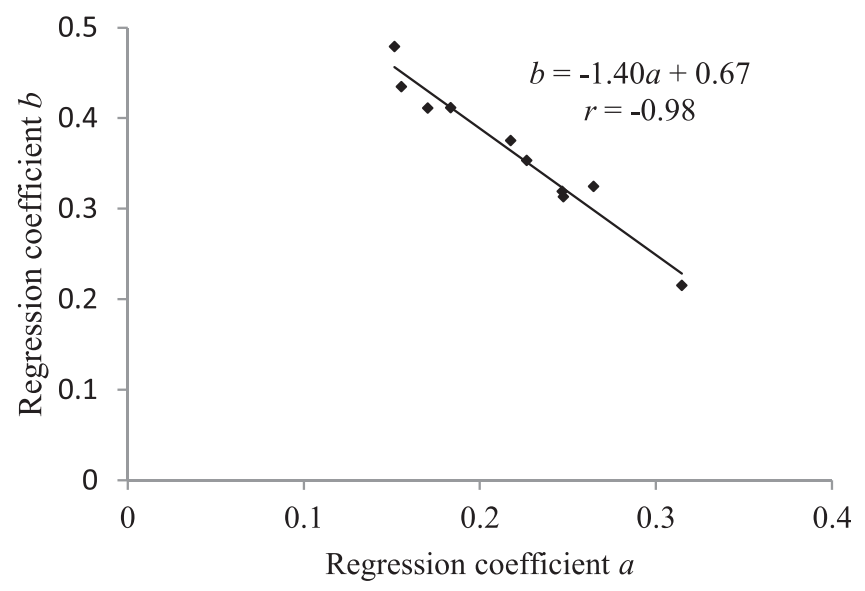

FIG. 5. Linear relationship between regression coefficients $b$ and $a$ for the yearly Angström-Prescott models for the period 2001-2010.

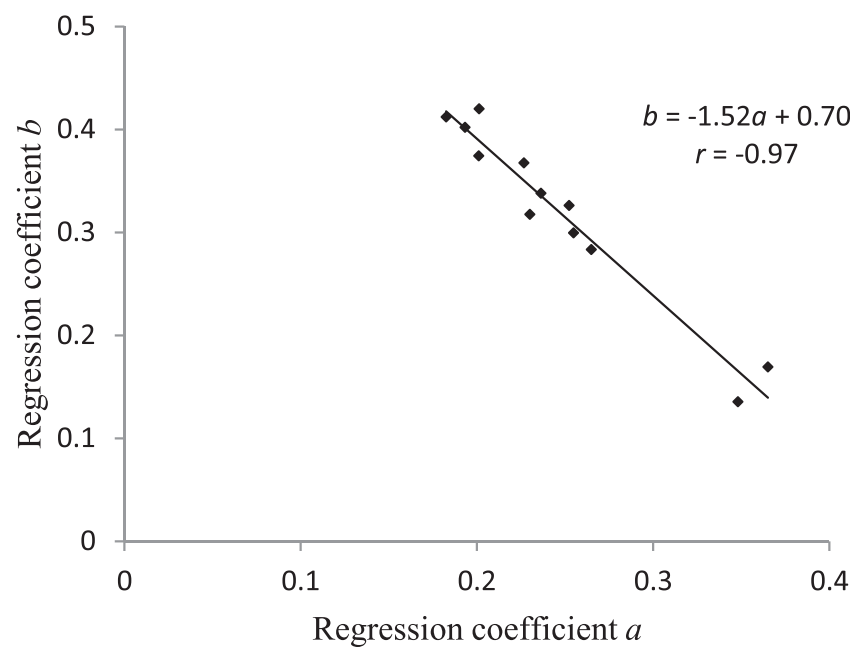

FIG. 6. Linear relationship between regression coefficients $b$ and $a$ for the twelve monthly Angström-Prescott models computed over the period 2001-2005.

coefficients close to -1 . It should be noted that monthly models derived by using ten years (as opposed to five years) gives a linear relationship between $b$ and $a$ as $b=-1.43 a+0.68$ with $r=-0.97$ which is in closer agreement with the linear relationship obtained from the ten yearly models. The difference between the linear relationships derived from the five-year monthly models and the ten-year monthly models is due to the different volume of data processed.

Various researchers have provided separate theoretical relations for $a$ and $b$ in terms of geographical and/or meteorological parameters (Rietveld, ${ }^{26}$ Gopinathan ${ }^{27}$ and Gopinathan ${ }^{28}$ ). Rietveld gave separate relations for $a$ and $b$ in terms of average fraction of sunshine hours $\left(\frac{\bar{n}}{N}\right)$. Gopinathan ${ }^{27}$ provided separate relations for $a$ and $b$ in terms of altitude and average fraction of sunshine hours while Gopinathan ${ }^{28}$ found $a$ and $b$ to be dependent on altitude, latitude, and average fraction of sunshine hours. From Rietveld, ${ }^{26}$ we derived $b=0.38+0.02 /(a-0.10)$ which is not linear and therefore not applicable to Trinidad. Similar analyses of Gopinathan ${ }^{27}$ and Gopinathan ${ }^{28}$ gave linear relationships between $b$ and $a$ as, $b=-2.41 a+1.41$ and $b=-1.24 a+0.79$, respectively, when applied to Trinidad for values of $10^{\circ} 35^{\prime} \mathrm{N}$ latitude and $21.95 \mathrm{~m}$ altitude at the location of the Trinidad and Tobago Meteorological Services. Although the latter two equations are linear, they do not agree with the linear relations obtained from the data used in our analysis. This suggests that models for $a$ and $b$ coefficients do not have global applicability and as such, models for $a$ and $b$ specific to Trinidad need to be developed. 


\section{F. Summary}

The five-year model, five-year dry and wet seasonal models, ten yearly models and twelve monthly models have been developed and evaluated and used to calculate global solar radiation in Trinidad with good accuracy for different time scales. It has been found that the five-year dry and wet seasonal models performed similarly to the five-year model and hence a single five-year model is suitable for predicting global solar radiation in Trinidad for any month of the year. Average daily and average total global solar radiation and number of sunshine hours were computed for the period 2001-2010 for the whole year, dry season, and wet season, as shown in Table V.

The ten yearly and the twelve monthly models were used in establishing linear relationships between the Angström-Prescott regression coefficients for a ten-year and one-year time scale.

\section{CONCLUSION}

Many solar energy applications require monthly average daily global solar radiation and average daily global solar radiation data to determine optimal system design. It is therefore of paramount importance that models to predict global solar radiation on different time scales be developed for use in solar energy applications. In Trinidad, data for sunshine hours are readily available from the Trinidad and Tobago Meteorological Services and therefore empirical Angström-Prescott models based on sunshine hours were developed and validated for different time scales. These models were: a five-year model, five-year dry and wet seasonal models, ten yearly models, and twelve five-year monthly models.

The regression coefficients, $(a, b)$ for the five-year, dry season, and wet season models were found to be $(0.21,0.38),(0.21,0.38)$, and $(0.27,0.28)$, respectively. The dry and wet seasonal models performed similarly to the five-year model and hence a single five-year model is suitable for predicting global solar radiation in Trinidad for any month of the year. For the ten yearly models, $a$ and $b$ varied over the ranges $0.15-0.31$ and $0.22-0.48$, respectively. For the monthly models, $a$ and $b$ varied over the ranges $0.19-0.37$ and $0.14-0.42$, respectively. Regression analysis of the coefficients from the ten yearly models and from the twelve monthly models established linear relationships between $b$ and $a$. Statistical test parameters: MBE, MPE, $R M S E, r, N S E$, and $p$-values were applied to all the models and the statistical analysis confirmed their applicability to Trinidad.

Finally, the average daily global solar radiation, average total global solar radiation, average daily number of sunshine hours, and average total number of sunshine hours were determined as: $16.93 \pm 0.73 \mathrm{MJ} \mathrm{m}^{-2} \mathrm{day}^{-1}, 2.56 \pm 0.11 \mathrm{GJ} \mathrm{m}^{-2}, 8.49 \pm 0.44 \mathrm{~h} \mathrm{day}^{-1}$, and $1282 \pm 67 \mathrm{~h}$, respectively, for the dry season; $15.52 \pm 0.81 \mathrm{MJ} \mathrm{m}^{-2}$ day $^{-1}, 3.32 \pm 0.17 \mathrm{GJ} \mathrm{m}^{-2}, 7.03 \pm 0.38 \mathrm{~h}$ day $^{-1}$, and $1504 \pm 81 \mathrm{~h}$, respectively, for the wet season; and $16.08 \pm 0.71 \mathrm{MJ} \mathrm{m}^{-2} \mathrm{day}^{-1}$, $5.87 \pm 0.26 \mathrm{GJ} \mathrm{m}^{-2}, 7.65 \pm 0.24 \mathrm{~h} \mathrm{day}^{-1}$, and $2792 \pm 83 \mathrm{~h}$, respectively, for the whole year.

\section{ACKNOWLEDGMENTS}

The authors recognize the invaluable contribution of the Trinidad and Tobago Meteorological Services for providing the data used in this study.

${ }^{1}$ T. Markvart, A. Fragaki, and J. N. Ross, Sol. Energy 80, 46 (2006).

${ }^{2}$ L. Martin, L. F. Zarzalejo, J. Polo, A. Navarro, R. Marchante, and M. Cony, Sol. Energy 84, 1772 (2010).

${ }^{3}$ R. De Jong and D. W. Stewart, Can. J. Plant Sci. 73, 509 (1993).

${ }^{4}$ T. Catalina, J. Virgone, and E. Blanco, Energy Build. 40, 1825 (2008).

${ }^{5} \mathrm{M}$. La Gennusa, A. Nucara, M. Pietrafesa, and G. Rizzo, Sol. Energy 81, 594 (2007).

${ }^{6}$ M. Bindi and F. Miglietta, Clim. Res. 1, 117 (1991).

${ }^{7}$ J. Almorox, C. Hontoria, and M. Benito, Appl. Energy 88, 1703 (2011).

${ }^{8}$ I. Korachagaon and V. N. Bapat, J. Renewable Sustainable Energy 4, 043101 (2012).

${ }^{9}$ A. A. El-Sebaii, F. S. Al-Hazmi, A. A. Al-Ghamdi, and S. J. Yaghmour, Appl. Energy 87, 568 (2010).

${ }^{10}$ H. Duzen and H. Aydin, Energy Convers. Manage. 58, 35 (2012).

${ }^{11}$ X. Y. Liu, X. R. Mei, Y. Z. Li, Y. Q. Zhang, Q. S. Wang, F. R. Jensen, and J. R. Porter, Agric. For. Meteorol. 149, 697 (2009). 
${ }^{12}$ L. T. Wong and W. K. Chow, Appl. Energy 69, 191 (2001).

${ }^{13}$ K. Bakirci, Energy 34, 485 (2009).

${ }^{14}$ J. A. Prescott, Trans. R. Soc. South Aust. 64, 114 (1940).

${ }^{15}$ M. Chegaar and A. Chibani, Energy Convers. Manage. 42, 967 (2001).

${ }^{16}$ Z. Sen, Sol. Energy 63, 39 (1998).

${ }^{17}$ E. Tulcan-Paulescu and M. Paulescu, Theor. Appl. Climatol. 91, 181 (2008).

${ }^{18}$ M. Mohandes, S. Rehman, and T. O. Halawani, Renewable Energy 14, 179 (1998).

${ }^{19}$ T. Khatib, A. Mohamed, M. Mahmoud, and K. Sopian, Int. J. Green Energy 8, 795 (2011).

${ }^{20}$ A. Zeroual, M. Ankrim, and A. J. Wilkinson, Renewable Energy 6, 787 (1995).

${ }^{21}$ S. A. Al-Awadhi and N. El-Nashar, Environmetrics 13, 751 (2002).

${ }^{22}$ G. W. Smith, Q. J. R. Meteorol. Soc. 86, 415 (1960).

${ }^{23}$ A. Angström, Q. J. R. Meteorol. Soc. 50, 121 (1924).

${ }^{24}$ J. A. Duffie and W. A. Beckman, Solar Engineering of Thermal Processes (John Wiley \& Sons, New York, 1991).

${ }^{25}$ Z. Sen, Solar Energy Fundamentals and Modelling Techniques: Atmosphere, Environment, Climate Change and Renewable Energy (Springer-Verlag, London, 2008).

${ }^{26}$ M. R. Rietveld, Agric. Meteorol. 19, 243 (1978).

${ }^{27}$ K. K. Gopinathan, Sol. Wind Technol. 5, 581 (1988).

${ }^{28}$ K. K. Gopinathan, Sol. Energy 41, 499 (1988). 